\title{
Added sugar in the packaged foods and beverages available at a major Canadian retailer in 2015: a descriptive analysis
}

\author{
Rachel B. Acton BSc, Lana Vanderlee PhD, Erin P. Hobin PhD, David Hammond PhD
}

Abstract

Background: Excess consumption of added sugars has been associated with a variety of health problems, but there is little information available characterizing added sugar in the Canadian food supply. This study examined the presence and types of added sugars in the packaged food and beverage products available at a major Canadian grocery retailer.

Methods: We searched the ingredients lists of over 40000 packaged food products available for sale in March 2015 for a variety of added sugar terms. Proportions of food products containing added sugar were identified overall and within food product categories. Differences in total sugar content were identified between food products with and without added sugar.

Results: Overall, $66 \%$ of the packaged food products analyzed contained at least 1 added sugar. The added sugar term "sugar" (and its variations) appeared the most frequently, followed by "dextrose." Added sugar presence and total sugar content varied within many product categories but were consistently higher in expected categories such as "beverages." Mean total sugar content was significantly higher in products with added sugar than in those without, both overall $(p<0.001)$ and within most product subcategories $(p<0.02)$.

Interpretation: About two-thirds of the packaged foods and beverages available at a major Canadian grocery retailer contain added sugar, similar to recent patterns estimated for the US food supply. The results provide an estimation of the baseline characterization of added sugar in the Canadian food supply, which can be used to assess outcomes of future changes to sugar labelling policies in Canada.

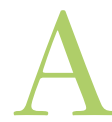

dded sugar has emerged as an important public health issue. The term "added sugar" generally refers to sugars (or ingredients that functionally substitute for sugars) that are added to foods and beverages during preparation or processing, in contrast to intrinsic sugars, which are found within the structure of intact fruits and vegetables, or sugars occurring naturally in milk. ${ }^{1}$ The World Health Organization has adopted the term "free sugars," which adds to the traditional definition of added sugar by encompassing the sugars naturally present in fruit juices and fruit juice concentrates. ${ }^{2}$ Higher intakes of added sugars threaten the nutrient quality of diets by replacing essential nutrients and increasing the overall energy density of diets. ${ }^{3}$ There is a growing body of evidence indicating that excess consumption of added sugar is associated with a variety of health problems, including heart disease, ${ }^{4-6}$ stroke, ${ }^{6}$ obesity, ${ }^{7-11}$ diabetes, ${ }^{12-16}$ high blood cholesterol levels, ${ }^{17,18}$ cancer $^{19}$ and dental caries..$^{20}$ The World Health Organization recom- mends reducing intake of free sugars to below $10 \%$ of total energy intake or, for additional health benefits, to less than $5 \% .^{2}$ Similarly, the Heart and Stroke Foundation of Canada recommends limiting consumption of added sugars to a maximum of $10 \%$ of total daily calorie intake, ${ }^{21}$ as do the 2015-2020 Dietary Guidelines for Americans. ${ }^{22}$

An increasing proportion of the food supply is categorized as processed and packaged foods, ${ }^{23}$ which tend to be high in added sugars. ${ }^{24}$ Worldwide, daily per capita consumption of

Competing interests: See the end of the article.

This article has been peer reviewed.

Correspondence to: David Hammond, david.hammond@uwaterloo.ca

CMAJ Open 2017. DOI:10.9778/cmajo.20160076 
caloric sweeteners (a term that excludes sugars added from fruit juice) increased by 74 calories from 1962 to $2000 .{ }^{25}$ Limited data are available on Canadians' added sugar consumption, but it has been estimated to fall between $11 \%$ and $13 \%$ of total energy intake. ${ }^{26,27}$ These global and Canadian estimates would increase substantially with the inclusion of sugar added from fruit juice, as suggested by the World Health Organization. There is little information about specific levels of added sugar in the food supply in general. Popkin and Hawkes $^{28}$ examined added sugar in the United States and found that, after low-calorie sweeteners were excluded, $68 \%$ of packaged foods and beverages available for purchase in 2013 contained added sugars. The primary objective of the current study was to examine the presence and types of added sugars in the packaged food and beverage products available at a major Canadian grocery retailer through an analysis of a comprehensive database of food product information. In particular, we sought to estimate the proportion of packaged food products with added sugar both overall and by food category, to identify the frequency of different types of added sugar and to identify differences in total sugar content between food products with and without added sugar.

\section{Methods}

\section{Setting}

We analyzed a comprehensive database containing food product information for over 60000 items available for sale in March 2015 across all banner stores of a major national grocery retailer. The retailer commands about one-third of the Canadian supermarket market share. Its stores are found in all 10 provinces as well as the Yukon Territory. The opportunity to access this unique resource of food product information was made available through an existing partnership with the retailer, which was originally established to examine a proprietary nutrition labelling system.

\section{Sources of data}

The data provided by the retailer included universal product code information, food product categories, product descriptions, information from the nutrition facts table and the ingredients lists of each food product. As this is a proprietary database, it is maintained by the retailer and is subject to internal data quality checks. The data set is updated weekly to add new and reformulated products and to remove discontinued items. Versions of this data set have been used to support various research studies in the US. ${ }^{29-31}$

To assess the comprehensiveness of the set of food products included in this database, we compared the universal product codes of the products in the database to supermarket transaction data recorded for Mar. 1, 2015 to Mar. 15, 2015. Over 150 million sales transactions were recorded in the retailer's stores across Canada over this 2-week period and included 60563 unique universal product codes. The results of this comparison indicated that $58 \%$ of the products analyzed in the current study were sold in the first 2 weeks of March. Most of the remaining products were likely seasonal or infrequently sold food items. The March sales transaction data also included 26711 universal product codes that were not among the food products analyzed in the current study. Just over half $(51 \%)$ of these were nonfood items, 9\% were discontinued products, and $37 \%$ were new products for which nutritional information had not yet been recorded; the remaining $3 \%$ was not explained by the retailer.

\section{Design}

For the purposes of this study, we included only packaged foods in the analysis. Products identified as fresh fruits or vegetables, fresh meat, raw ingredients (e.g., water, baking ingredients, coffee and tea, fats and oils) or nonfood items (e.g., natural health products, nutrition and protein supplements) were excluded.

\section{Measures}

Various terms are used in the literature to describe sugars. ${ }^{32}$ Traditionally, the term "added sugars" refers to all sugars added to foods, including honey and syrups, but does not necessarily include fruit juices or fruit juice concentrates. ${ }^{1}$ The World Health Organization has adopted the term "free sugars" with the intention of creating a more precise definition and defines it as all "monosaccharides and disaccharides added to foods and beverages by the manufacturer, cook or consumer, and sugars naturally present in honey, syrups, fruit juices and fruit juice concentrates." $W$ e used this definition of free sugars to identify added sugars in the current study. We searched for 30 different added sugar terms in the ingredients lists of the food products: agave, malt/barley malt, cane juice, caramel, carob, corn sweetener, corn syrup, date paste, dextran, dextrose, diastase, ethyl maltol, Florida crystals, fructose, fruit juice concentrate, galactose, glucose, glucosefructose, high-fructose corn syrup, honey, lactose, maltodextrin, maltose, molasses, nectar, panocha, sucrose, sugar, syrup and treacle. ${ }^{33-35}$ General terms such as "sugar" or "syrup" contained multiple varieties of added sugars (e.g., "icing sugar," "grape sugar," "raw sugar," "rice syrup," "golden syrup"). Terms more commonly recognized on their own, such as "corn syrup," were included in independent categories. The search method accounted for sugars with overlapping names, such as "fructose" and "high-fructose corn syrup," and excluded unwanted nonsugar ingredients that might be identified with the search terms, such as "boneydew melon" or "caramelized onions." Like previous researchers, ${ }^{28,36}$ we excluded sugar alcohols such as sorbitol, glycerol and erythritol from our search, as they contain insignificant amounts of energy. All added sugar terms can be found in Table 1.

"Total sugar," as opposed to added sugar, indicates the total grams of sugar in 1 serving of a food product, including added, intrinsic and milk sugars. ${ }^{1}$ We identified total sugar using an existing variable in the database that provided grams of sugar per serving, as listed on the product's nutrition facts table. We standardized this information to total grams of sugar per $100 \mathrm{~g}$ or $100 \mathrm{~mL}$ of the product, using the serving size and serving size unit of measurement of each product. 
The food products were sorted into 10 categories (milk and dairy; protein foods; mixed dishes; grains; baked goods; snacks and sweets; beverages; condiments, sauces and spreads; infant formula and baby food; and fruits and vegetables) and 30 subcategories. We adapted these categories from those used in the What We Eat in America dietary intake component of the National Health and Nutrition Examination Survey. ${ }^{37}$

\section{Statistical analysis}

We used the COUNTIF functions in Excel 2013 to search for each added sugar term, including searches for variations in spelling and punctuation. We used SPSS software version 22.0 to perform descriptive statistical analyses (counts, means, standard deviations and proportions) and to conduct $t$ tests to analyze differences in total sugar between products with and without added sugars.

\begin{tabular}{|c|c|c|}
\hline Added sugar & $\begin{array}{c}\text { No. }(\%) \text { of all } \\
\text { products } \\
(n=40829)\end{array}$ & $\begin{array}{c}\% \text { of products } \\
\text { with added } \\
\text { sugar } \\
(n=26942)\end{array}$ \\
\hline Sugar (all other) & 21869 (53.6) & 81.2 \\
\hline Dextrose & $4892(12.0)$ & 18.2 \\
\hline Glucose & $3847(9.4)$ & 14.3 \\
\hline Glucose-fructose & $3555(8.7)$ & 13.2 \\
\hline Corn syrup & $3181(7.8)$ & 11.8 \\
\hline Maltodextrin & $3015(7.4)$ & 11.2 \\
\hline Fruit juice concentrate & $2278(5.6)$ & 8.5 \\
\hline Honey & $1596(3.9)$ & 5.9 \\
\hline Molasses & $1486(3.6)$ & 5.5 \\
\hline Syrup (all other) & $1177(2.9)$ & 4.4 \\
\hline Lactose & $885(2.2)$ & 3.3 \\
\hline Fructose & $742(1.8)$ & 2.8 \\
\hline Cane juice & $706(1.7)$ & 2.6 \\
\hline Malt/barley malt & $400(1.0)$ & 1.5 \\
\hline $\begin{array}{l}\text { High-fructose corn } \\
\text { syrup }\end{array}$ & $361(0.9)$ & 1.3 \\
\hline Caramel & $302(0.7)$ & 1.1 \\
\hline Agave & $190(0.5)$ & 0.7 \\
\hline Sucrose & $125(0.3)$ & 0.5 \\
\hline Date paste & $40(0.1)$ & 0.1 \\
\hline Maltose & $27(0.1)$ & 0.1 \\
\hline Carob & $10(<0.1)$ & $<0.1$ \\
\hline Treacle & $7(<0.1)$ & $<0.1$ \\
\hline Ethyl maltol & $6(<0.1)$ & $<0.1$ \\
\hline Corn sweetener & $4(<0.1)$ & $<0.1$ \\
\hline $\begin{array}{l}\text { Nectar (other than } \\
\text { agave) }\end{array}$ & $4(<0.1)$ & $<0.1$ \\
\hline
\end{tabular}

\section{Results}

We analyzed 40829 packaged food products, of which 26942 $(66.0 \%)$ contained at least 1 added sugar in their ingredients list.

\section{Types of added sugar}

Table 1 shows the frequency and proportion at which each different added sugar term appeared in the products examined. The most common added sugar term was "sugar," identified in 21869 (53.6\%) of all food products analyzed. The next 5 most frequently appearing terms (dextrose, glucose, glucose-fructose, corn syrup and maltodextrin) were found in 18490 food products (45.3\%), collectively. Dextran, diastase, Florida crystals, galactose and panocha did not appear in any of the food products analyzed.

\section{Sugar content}

The mean amount of total sugar present in the food products is shown in Table 2. Overall, products in the "snacks and sweets" category contained the highest mean level of total sugar. Total sugar levels were highly variable across the subcategories of the "snacks and sweets" and "grains" categories. The "condiments, sauces and spreads," "infant formula and baby food," "beverages" and "fruits and vegetables" categories contained the next highest levels of total sugar. The remaining categories ("protein foods," "mixed dishes," "baked goods" and "milk and dairy") all contained relatively lower levels of total sugars in comparison to the other categories.

Table 2 also shows the proportion of foods in each subcategory that contained at least 1 added sugar in their ingredients list, according to the search method. These results followed a similar pattern to mean total sugar, with high proportions of added sugar in the categories with high total sugar. Some notable exceptions included the "red meat and poultry," "cured meats," "soups," "pizza," "Mexican" and "breads" subcategories, in which a high proportion of the products contained at least 1 added sugar but the mean total sugar content was relatively low.

\section{Total sugar in products with and without added sugar}

The mean amount of total sugar found in products identified as having added sugar and in those without is shown by subcategory in Table 2. The overall mean total sugar in products with added sugar was significantly higher than that in products without added sugar, at $19.8 \mathrm{~g}$ and $3.0 \mathrm{~g}$, respectively $(t=$ $-89.387, p<0.001)$. There were also significant differences in total sugar content between products with and without added sugar within most of the subcategories ( $p<0.02$ in all cases), with the exception of the subcategories "dairy drinks and substitutes" ( $p=0.1)$, "pizza" $(p=0.07)$, "Mexican" $(p=0.2)$, "snack/meal bars" ( $p=0.09)$ and "beverage mixes and crystals" $(p=0.2)$.

The search strategy identified 2311 food products that contained $0 \mathrm{~g}$ of total sugar per serving but were identified as having at least 1 added sugar in their ingredients list. This 
Table 2: Total sugar and added sugar by food product category and subcategory

\begin{tabular}{|c|c|c|c|c|c|}
\hline Category/subcategory & $\begin{array}{c}\text { Mean total } \\
\text { sugar, } \\
\mathrm{g} / 100 \mathrm{~g} \text { or } \\
\mathrm{g} / 100 \mathrm{~mL} \pm \mathrm{SD}\end{array}$ & $\begin{array}{l}\text { No. }(\%) \text { with } \\
\text { added sugar }\end{array}$ & $\begin{array}{l}\text { Mean total sugar } \\
\text { in products } \\
\text { without added } \\
\text { sugar, } \\
\mathrm{g} / 100 \mathrm{~g} \text { or } \\
\mathrm{g} / 100 \mathrm{~mL} \pm \mathrm{SD}\end{array}$ & $\begin{array}{l}\text { Mean total sugar } \\
\text { in products with } \\
\text { added sugar, } \\
\text { g/100 g or } \\
\text { g/100 mL } \pm \mathrm{SD}\end{array}$ & $\begin{array}{c}\text { Absolute } \\
\text { difference } \\
\text { in total } \\
\text { sugar, g* }\end{array}$ \\
\hline Milk and dairy $(n=5415)$ & $4.7 \pm 5.9$ & $1603(29.6)$ & $2.1 \pm 3.2$ & $10.7 \pm 6.4$ & $8.5 \ddagger$ \\
\hline All milk, cream $(n=1374)$ & $7.1 \pm 6.1$ & $447(32.5)$ & $4.8 \pm 1.4$ & $11.7 \pm 8.7$ & $6.9 \ddagger$ \\
\hline Dairy drinks and substitutes $(n=176)$ & $3.7 \pm 3.8$ & $111(63.1)$ & $1.4 \pm 2.1$ & $5.1 \pm 3.8$ & 3.7 \\
\hline Cheese $(n=2862)$ & $1.7 \pm 4.2$ & $305(10.6)$ & $1.0 \pm 3.2$ & $8.1 \pm 6.4$ & $7.1 \ddagger$ \\
\hline Yogourt $(n=1003)$ & $9.9 \pm 4.8$ & $740(73.8)$ & $4.0 \pm 1.9$ & $12.0 \pm 3.6$ & $8.0 \ddagger$ \\
\hline Protein foods $(n=4989)$ & $2.7 \pm 6.4$ & $2826(56.6)$ & $2.1 \pm 4.2$ & $3.2 \pm 7.6$ & $1.1 \ddagger$ \\
\hline Red meat, poultry $(n=497)$ & $2.1 \pm 3.0$ & $339(68.2)$ & $0.6 \pm 1.1$ & $2.8 \pm 3.3$ & $2.2 \ddagger$ \\
\hline Fish, seafood $(n=645)$ & $1.3 \pm 4.4$ & $283(43.9)$ & $0.1 \pm 0.6$ & $2.8 \pm 6.3$ & $2.7 \ddagger$ \\
\hline Cured meats $(n=2123)$ & $1.5 \pm 4.6$ & $1804(85.0)$ & $0.7 \pm 5.7$ & $1.7 \pm 4.4$ & $1.0 \dagger$ \\
\hline Canned fish/meats $(n=456)$ & $0.9 \pm 2.6$ & $139(30.5)$ & $0.1 \pm 0.6$ & $2.7 \pm 4.1$ & $2.5 \ddagger$ \\
\hline Plant-based protein foods $(n=1268) \S$ & $6.3 \pm 9.6$ & $261(20.6)$ & $4.0 \pm 4.5$ & $15.0 \pm 16.6$ & $10.9 \ddagger$ \\
\hline Mixed dishes $(n=3989)$ & $3.5 \pm 4.5$ & $3023(75.8)$ & $1.8 \pm 3.7$ & $4.1 \pm 4.6$ & $2.3 \ddagger$ \\
\hline Soups $(n=896)$ & $4.5 \pm 6.2$ & $701(78.2)$ & $2.1 \pm 5.5$ & $5.1 \pm 6.3$ & $3.0 \ddagger$ \\
\hline Pizza $(n=327)$ & $3.1 \pm 1.7$ & $322(98.5)$ & $2.4 \pm 0.3$ & $3.1 \pm 1.7$ & 0.6 \\
\hline Mexican $(n=41)$ & $2.1 \pm 1.2$ & $31(75.6)$ & $1.0 \pm 0.7$ & $2.5 \pm 1.1$ & 1.5 \\
\hline Frozen dinners/entrees $(n=823)$ & $2.8 \pm 3.0$ & $611(74.2)$ & $1.6 \pm 1.6$ & $3.3 \pm 3.2$ & $1.7 \ddagger$ \\
\hline Other $(n=1902)$ & $3.5 \pm 4.4$ & $1358(71.4)$ & $1.8 \pm 3.6$ & $4.2 \pm 4.5$ & $2.4 \ddagger$ \\
\hline Grains $(n=2364)$ & $7.5 \pm 10.9$ & $899(38.0)$ & $1.6 \pm 3.1$ & $17.1 \pm 12.2$ & $15.5 \ddagger$ \\
\hline Cereals $(n=719) \emptyset$ & $19.7 \pm 12.2$ & $616(85.7)$ & $2.0 \pm 4.4$ & $22.7 \pm 10.4$ & $20.7 \ddagger$ \\
\hline Other $(n=1645)^{\star *}$ & $2.1 \pm 3.4$ & $283(17.2)$ & $1.6 \pm 2.9$ & $4.8 \pm 4.4$ & $3.2 \ddagger$ \\
\hline Bread products†† ( $n=2093)$ & $3.8 \pm 4.4$ & $1478(70.6)$ & $1.6 \pm 2.8$ & $4.7 \pm 4.6$ & $3.1 \ddagger$ \\
\hline Snacks and sweets $(n=12534)$ & $27.4 \pm 22.1$ & $10780(86.0)$ & $3.0 \pm 8.3$ & $31.4 \pm 21.1$ & $28.4 \ddagger$ \\
\hline Savory snacks $(n=2716)$ & $6.2 \pm 11.0$ & $1453(53.5)$ & $2.5 \pm 7.8$ & $9.4 \pm 12.2$ & $6.9 \ddagger$ \\
\hline Crackers $(n=849)$ & $6.4 \pm 8.2$ & $585(68.9)$ & $1.7 \pm 3.0$ & $8.5 \pm 8.9$ & $6.8 \ddagger$ \\
\hline Snack/meal bars $(n=338)$ & $31.4 \pm 9.3$ & $336(99.4)$ & $0.0 \pm 0.0$ & $31.6 \pm 9.0$ & 31.6 \\
\hline Sweet bakery products $(n=3575)$ & $29.4 \pm 13.2$ & $3493(97.7)$ & $4.1 \pm 7.5$ & $30.0 \pm 12.7$ & $25.9 \ddagger$ \\
\hline Candy $(n=3468)$ & $51.7 \pm 17.7$ & $3384(97.6)$ & $13.2 \pm 17.7$ & $52.7 \pm 16.6$ & $39.5 \dagger$ \\
\hline Other $(n=1588)$ & $16.7 \pm 10.4$ & $1529(96.3)$ & $3.6 \pm 5.0$ & $17.2 \pm 10.3$ & $13.6 \ddagger$ \\
\hline Beverages $(n=3161)$ & $12.5 \pm 19.5$ & $2487(78.7)$ & $3.9 \pm 7.5$ & $14.8 \pm 21.2$ & $10.9 \ddagger$ \\
\hline Juice $(n=1748) \ddagger \ddagger$ & $14.9 \pm 19.4$ & $1386(79.3)$ & $6.9 \pm 5.1$ & $17.0 \pm 21.1$ & $10.2 \ddagger$ \\
\hline Pop/soda, iced teas $(n=845)$ & $8.2 \pm 6.3$ & $649(76.8)$ & $0.2 \pm 1.2$ & $10.6 \pm 5.0$ & $10.4 \ddagger$ \\
\hline $\begin{array}{l}\text { Sports drinks, energy drinks, flavoured } \\
\text { water }(n=520)\end{array}$ & $12.0 \pm 30.6$ & $406(78.1)$ & $1.3 \pm 2.8$ & $15.1 \pm 34.0$ & $13.8 \ddagger$ \\
\hline Beverage mixes, crystals $(n=48) \ddagger \ddagger$ & $6.8 \pm 1.8$ & $46(95.8)$ & $3.2 \pm 0.0$ & $7.0 \pm 1.6$ & 3.8 \\
\hline $\begin{array}{l}\text { Condiments, sauces and spreads } \\
(n=4149) \S \S\end{array}$ & $20.9 \pm 25.9$ & $3034(73.1)$ & $3.4 \pm 7.5$ & $27.3 \pm 27.2$ & $23.9 \ddagger$ \\
\hline Baby food and cereals $(n=530)$ & $13.3 \pm 13.6$ & $253(47.7)$ & $7.6 \pm 9.4$ & $19.5 \pm 14.8$ & $11.9 \ddagger$ \\
\hline Fruits and vegetables $(n=1605)$ ๆी & $12.4 \pm 19.3$ & $559(34.8)$ & $9.1 \pm 17.3$ & $18.5 \pm 21.2$ & $9.4 \ddagger$ \\
\hline Total $(n=40829)$ & $14.1 \pm 19.8$ & $26942(66.0)$ & $3.0 \pm 7.1$ & $19.8 \pm 21.6$ & $16.8 \ddagger$ \\
\hline \multicolumn{6}{|c|}{ 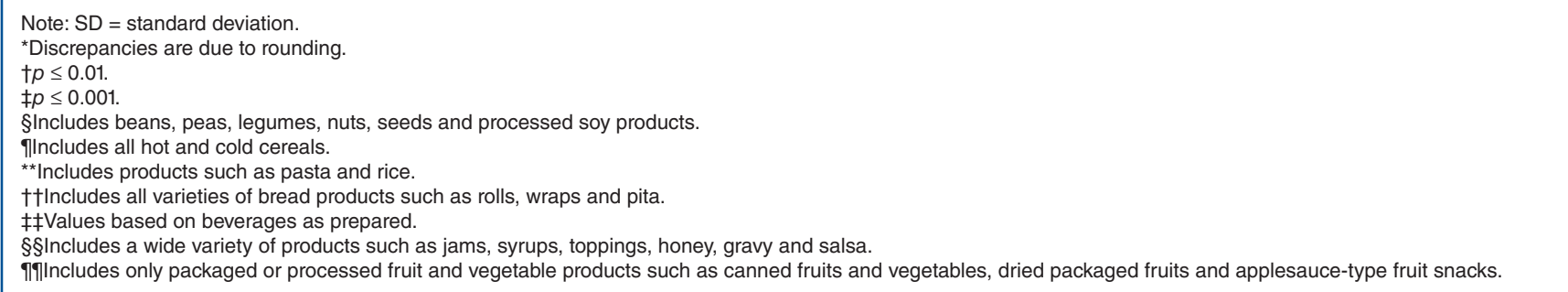 } \\
\hline
\end{tabular}


discrepancy may be primarily explained by the fact that Canada's guidelines for the nutrition facts table allow manufacturers to list the amount of total sugar as $0 \mathrm{~g}$ if 1 serving of the food product contains less than $0.5 \mathrm{~g}$ of total sugar. ${ }^{38}$

\section{Interpretation}

We found that about two-thirds of the packaged food products sold in a major Canadian supermarket retailer contain added sugar. These results are comparable to estimates reported by Popkin and Hawkes ${ }^{28}$ in the US and suggest a high level of consistency in added sugar presence across the North American food supply. Given the company's widespread permeation across Canada, it is reasonable to argue that the sample of over 40000 food products analyzed in this study is a realistic approximation of the entire Canadian packaged food supply.

The added sugar term most commonly identified in ingredients lists ("sugar" and its variations) may be familiar to consumers, but numerous lesser-known terms, which consumers may not recognize as added sugars, also appear frequently. This diverse terminology may pose a challenge for consumers trying to identify whether a product contains added sugar. The presence of added sugar was highest in the expected food products, including candy, sweet bakery products and soft drinks, but was also very high in food products that many consumers choose as "healthy" options, such as snack bars, cereal and juice. In general, mean amounts of total sugar were highest in the food categories that had a high presence of added sugar. Foods that contain added sugar tend to have significantly higher total sugar contents than those without added sugar. Some exceptions to this observation were the "pizza" and "Mexican" food product categories, both of which had very high proportions of products containing added sugar but relatively low mean total sugar contents. These discrepancies indicate that, although most of the products in those food categories do contain added sugar, the average amount of added and intrinsic sugars across those products is very small.

Little is known about consumers' level of knowledge and awareness of added sugars in food products. However, evidence suggests that consumers have several misunderstandings about sugars and sugar processing, including confusion about the safest ways to consume sugars in a healthy diet and the belief that sugar content of fruit juice is less of a health risk than that of soft drinks. ${ }^{39}$ Furthermore, around one-quarter of Canadians aged 16-24 years cannot identify whether there is added sugar present in a food item when there is no information about added sugar on the nutrition facts table. ${ }^{40}$ In an effort to address the confusion over added sugars, the US has recently finalized updates to their nutrition facts label that include requirements to distinguish between intrinsic and added sugars, with a percent daily value for added sugars based on the US Department of Agriculture recommendation that they not exceed $10 \%$ of total daily calories. ${ }^{41}$ Health Canada has also recently considered the addition of an added sugar value on nutrition facts tables as well as a reorganization of the ingredients list that would group all sugars together in a set of brackets, which may aid consumers in finding and reading added sugars in the list of ingredients. ${ }^{42,43}$ Health Canada's plans indicate that the traditional definition of added sugars will be adopted, rather than including sugars added from fruit juice. If the "free sugars" definition is not adopted, there will be a missed opportunity to reduce the health "halo effect" surrounding sugars consumed via fruit juices.

\section{Strengths and limitations}

The products in this study came from the largest food retailer in Canada across of a range of supermarket "banners"; however, the data did not include products from other retailers. In addition, the food product data used in this study were not linked with supermarket transaction data; therefore, the results reflect what is available for purchase rather than salesweighted data on consumer purchasing behaviours. Despite these limitations, the product database that we analyzed represents the largest database of prepackaged foods in Canada of which we are aware.

Not all of the products in the food database were sold within the 2-week period for which sales data was available. However, there were no substantial differences between the presence of added sugar in the 40829 products analyzed (66.0\% of which contained added sugar) and those that were verified as sold between Mar. 1, 2015, to Mar. 15, 2015 (67.2\% of which contained added sugar). We decided to include all products reported in the food database (as opposed to only those sold during the 2 -week period) because this would provide a more comprehensive analysis of seasonal and nonseasonal products that may not be captured in sales transactions over a single 2 -week period.

The number of different ways in which added sugar is reported as an ingredient represented an additional challenge. We attempted to include all relevant ingredients; however, the search strategy may have overlooked some new or rare terms for added sugar.

\section{Conclusion}

A high proportion of the prepackaged foods and beverages available at Canada's largest grocery retailer contain added sugar. Our findings underscore the prevalence of added sugar in the Canadian food supply as well as the difficulty of identifying added sugar content, which requires a detailed understanding of the many ways in which added sugar is reported as an ingredient. In the absence of requirements to report added sugar levels in nutrition labels, Canadian consumers lack the information necessary to act on public health recommendations to limit added sugar consumption.

\section{References}

1. Dietary carbohydrates: sugars and starches. In: Dietary reference intakes for energy, carbobydrate, fiber, fat, fatty acids, cholesterol, protein, and amino acids. Washington: National Academies Press; 2002:265-338.

2. Guideline: sugars intake for adults and children. Geneva: World Health Organization; 2015. Available: http://apps.who.int/iris/bitstream/10665/149782/ 1/9789241549028_eng.pdf?ua=1 (accessed 2015 Dec. 17).

3. Murphy P, Johnson R. The scientific basis of recent US guidance on sugars intake. Am 7 Clin Nutr 2003;78:8275-335. 
4. Yang Q, Zhang Z, Gregg EW, et al. Added sugar intake and cardiovascular disease mortality among US adults. 7AMA Intern Med 2014;174:516-24.

5. Johnson RK, Appel LJ, Brands M, et al. Dietary sugars intake and cardiovascular health: a scientific statement from the American Heart Association. Circulation 2009;120:1011-20.

6. Liu S, Willett WC, Stampfer MJ, et al. A prospective study of dietary glycemic load, carbohydrate intake, and risk of coronary heart disease in US women. Am 7 Clin Nutr 2000;71:1455-61.

7. Bray GA, Nielsen SJ, Popkin BM. Consumption of high-fructose corn syrup in beverages may play a role in the epidemic of obesity. Am 7 Clin Nutr 2004;79:537-43.

8. Pollock NK, Bundy V, Kanto W, et al. Greater fructose consumption is associated with cardiometabolic risk markers and visceral adiposity in adolescents. 7 Nutr 2012;142:251-7.

9. Sievenpiper JL, de Souza RJ, Mirrahimi A, et al. Effect of fructose on body weight in controlled feeding trials: a systematic review and meta-analysis. Ann Intern Med 2012;156:291-304.

10. Te Morenga L, Mallard S, Mann J. Dietary sugars and body weight: systematic review and meta-analyses of randomised controlled trials and cohort studies. BMF 2013;346:e7492.

11. Wang H, Steffen LM, Zhou X, et al. Consistency between increasing trends in added-sugar intake and body mass index among adults: the Minnesota Heart Survey, 1980-1982 to 2007-2009. Am 7 Public Health 2013;103:501-7.

12. Basu S, Yoffe P, Hills $\mathrm{N}$, et al. The relationship of sugar to population-level diabetes prevalence: an econometric analysis of repeated cross-sectional data. PLoS One 2013;8:e57873.

13. Cozma AI, Sievenpiper JL, de Souza RJ, et al. Effect of fructose on glycemic control in diabetes: a systematic review and meta-analysis of controlled feeding trials. Diabetes Care 2012;35:1611-20.

14. Davis JN, Ventura EE, Weigensberg MJ, et al. The relation of sugar intake to beta cell function in overweight Latino children. Am 7 Clin Nutr 2005;82: 1004-10.

15. Gross LS, Li L, Ford ES, et al. Increased consumption of refined carbohydrates and the epidemic of type 2 diabetes in the United States: an ecologic assessment. Am $\mathcal{F}$ Clin Nutr 2004;79:774-9.

16. Janket SJ, Manson JE, Sesso H, et al. A prospective study of sugar intake and risk of type 2 diabetes in women. Diabetes Care 2003;26:1008-15.

17. Sievenpiper JL, Carleton AJ, Chatha S, et al. Heterogeneous effects of fructose on blood lipids in individuals with type 2 diabetes: systematic review and meta-analysis of experimental trials in humans. Diabetes Care 2009;32: 1930-7.

18. Welsh JA, Sharma A, Abramson JL, et al. Caloric sweetener consumption and dyslipidemia among US adults. FAMA 2010;303:1490-7.

19. Larsson SC, Bergkvist L, Wolk A. Consumption of sugar and sugarsweetened foods and the risk of pancreatic cancer in a prospective study. $\mathrm{Am}$ 7 Clin Nutr 2006;84:1171-6.

20. Moynihan PJ, Kelly SAM. Effect on caries of restricting sugars intake: systematic review to inform WHO guidelines. 7 Dent Res 2014;93:8-18.

21. Sugar and your health. Heart and Stroke Foundation of Canada; 2014. Available: www.heartandstroke.com/site/apps/nlnet/content2.aspx?c=ikIQLcMWJtE\&b= 4016859\&ct=14183373 (accessed 2015 Dec. 17).

22. 2015-2020 dietary guidelines for Americans. 8th edition. Washington: US Department of Health and Human Services and US Department of Agriculture; 2015. Available: http://health.gov/dietaryguidelines/2015/guidelines (accessed 2016 Nov. 23).

23. Popkin BM. Nutritional patterns and transitions. Popul Dev Rev 1993;19:138-57.

24. Drewnowski A, Rehm CD. Consumption of added sugars among US children and adults by food purchase location and food source. Am 7 Clin Nutr 2014;100:901-7.

25. Popkin BM, Nielsen SJ. The sweetening of the world's diet. Obes Res 2003; 11:1325-32.

26. Brisbois TD, Marsden SL, Anderson GH, et al. Estimated intakes and sources of total and added sugars in the Canadian diet. Nutrients 2014;6:1899-912.

27. Srinivasan CS, Irz X, Shankar B, et al. An assessment of the potential consumption impacts of WHO dietary norms in OECD countries. Food Policy 2005;31:53-77

28. Popkin BM, Hawkes C. Sweetening of the global diet, particularly beverages: patterns, trends, and policy responses. Lancet Diabetes Endocrinol 2016;4: 174-86.

29. Cawley J, Sweeney MJ, Sobal J, et al. The impact of a supermarket nutrition rating system on purchases of nutritious and less nutritious foods. Public Health Nutr 2015;18:8-14.

30. Rahkovsky I, Lin BH, Lin CTJ, et al. Effects of the Guiding Stars Program on purchases of ready-to-eat cereals with different nutritional attributes. Food Policy 2013;43:100-7.
31. Sutherland LA, Kaley LA, Fischer L. Guiding Stars: the effect of a nutrition navigation program on consumer purchases at the supermarket. Am 7 Clin Nutr 2010;91:1090S-4S

32. Mann J, Fleck F. The science behind the sweetness in our diets. Bull World Health Organ 2014;92:780-1.

33. What we eat in America food categories. Washington: United States Department of Agriculture; 2012. Available: www.ars.usda.gov/SP2UserFiles/ Place/80400530/pdf/1112/food_category_list.pdf (accessed 2015 Dec. 17).

34. What are added sugars? Washington: United States Department of Agriculture; 2016. Available: www.choosemyplate.gov/what-are-added-sugars (accessed 2016 Apr. 11).

35. Added sugar in the diet. Boston: Harvard TH Chan School of Public Health; 2015. Available: www.hsph.harvard.edu/nutritionsource/carbohydrates/ added-sugar-in-the-diet (accessed 2015 Dec. 17).

36. 61 names for sugar. SugarScience; 2015. Available: www.sugarscience.org/ hidden-in-plain-sight/\#.Vm8Wh1 UrJaQ (accessed 2015 Dec. 17).

37. Guidance for industry: a food labeling guide. Silver Spring (MD): US Food and Drug Administration; 2013. Available: www.fda.gov/Food/GuidanceRegulation/ GuidanceDocumentsRegulatoryInformation/LabelingNutrition/ucm064911.htm (accessed 2015 Dec. 17).

38. Regulations amending the food and drug regulations (nutrition labelling, nutrient content claims and health claims). Canada Gazette Part II 2003;137:165 (SOR/2003-11). Available: http://publications.gc.ca/gazette/archives/p2/ 2003/2003-01-01/pdf/g2-13701.pdf (accessed 2015 Dec. 17).

39. Working group report. Sugars: improving information and messages to consumers. Watford (UK): Institute of Grocery Distribution; 2010. Available: http:// shoppervista.igd.com/sitecontent/dotcomcontent/samplepages/Sugars $\% 20$ -\%20Improving\%20information \%20and\%20messages\%20to\%20consumers.pdf (accessed 2015 Dec. 17).

40. Vanderlee L, White CM, Bordes I, et al. The efficacy of sugar labeling formats: implications for labeling policy. Obesity (Silver Spring) 2015;23:2406-13.

41. Proposed changes to the nutrition facts label. Silver Spring (MD): US Food and Drug Administration; 2015. Available: www.fda.gov/Food/GuidanceRegulation/ GuidanceDocumentsRegulatoryInformation/LabelingNutrition/ucm 385663. htm (accessed 2015 Dec. 17).

42. Proposed food label changes. Government of Canada; 2015. Available: www. healthycanadians.gc.ca/health-system-systeme-sante/consultations/food-label -etiquette-des-aliments/index-eng.php (accessed 2016 Apr. 11).

43. Nutrition labelling — table of daily values. Government of Canada; 2015. Available: http://healthycanadians.gc.ca/health-system-systeme-sante/consultations/ food-label-etiquette-des-aliments/daily-values-valeurs-quotidiennes-eng.php (accessed 2016 Jan. 28).

Affiliations: School of Public Health and Health Systems (Acton, Vanderlee, Hobin, Hammond), University of Waterloo, Waterloo, Ont.; Department of Nutritional Sciences (Vanderlee) and Dalla Lana School of Public Health (Hobin), University of Toronto, Toronto, Ont.; Public Health Ontario (Hobin, Hammond), Toronto, Ont.

Contributors: Rachel Acton participated in designing the study, developing the research questions, conducting the analyses and writing the initial draft of the manuscript. Lana Vanderlee and David Hammond participated in designing the study methods and developing the research questions. Erin Hobin participated in acquiring the data. All of the authors participated in interpreting the data and revising the document for important intellectual content, approved the final version to be published and agreed to act as guarantors of the work.

Competing interests: Rachel Acton received a master's scholarship grant from the Canadian Institutes of Health Research during the conduct of the study. Lana Vanderlee received scholarship grants (doctoral and postdoctoral) from the Canadian Institutes of Health Research during the conduct of the study. David Hammond is a Chair in Applied Public Health, funded by the Public Health Agency of Canada in partnership with the Canadian Institutes of Health Research Institute of Neurosciences, Mental Health and Addiction, and Institute of Population and Public Health. He has provided paid expert testimony on behalf of public health authorities in response to legal challenges from the food and beverage industry.

Supplemental information: For reviewer comments and the original submission of this manuscript, please see www.cmajopen.ca/content/5/1/ E1/suppl/DC1 